\title{
O fetiche na fotografia de moda e a representação feminina: editoriais da revista Vogue Brasil de 2007 a 2011
}

\begin{abstract}
Resumo
O fetiche, conceituado de acordo com a Psicanálise, está muito presente hoje em várias áreas do conhecimento e na mídia. A sua popularização deve-se em grande parte ao mundo fashion, com o surgimento das revistas femininas de moda no final do séc. XIX e, desde então, a sua aparição em editoriais de moda pode ser verificada. Mas com que frequência? Quais são os acessórios e vestuários fetichistas que são utilizados nos editoriais de moda nessa análise, os editoriais da revista Vogue Brasil, durante os anos de 2007 a 2011 - e quais são as poses e trejeitos relacionados ao fetiche que estão presentes nas fotografias dos editoriais? É o que a nossa análise pretende responder, inserindo os resultados numéricos em uma análise qualitativa das imagens e no seu contexto contemporâneo da sociedade, identificando a representação feminina - e masculina, por conseguinte - no contexto dos editoriais de moda da Revista Vogue Brasil.
\end{abstract}

Palavras-chave: Fetiche; Fotografia de moda; Editorial de moda; Vogue Brasil; Representação de gênero.

\author{
Amanda Gomes de Ourofino \\ Mestre em Comunicação pela \\ Universidade de Brasília - UnB - \\ Brasil \\ amanda.ourofino@gmail.com
}

\section{Para citar este artigo:}

OUROFINO, Amanda Gomes. O fetiche na fotografia de moda e a representação feminina: editoriais da revista Vogue Brasil de 2007 a 2011. Revista Linhas. Florianópolis, v. 16, n. 32, p. 221 - 245, set./dez. 2015. 


\title{
The fetish in fashion photography and the feminine representation: Vogue Brazil magazine essays from 2007 to 2011
}

\begin{abstract}
Fetish, as defined in Psychoanalysis, is currently present in several areas of knowledge as well as in the media. Its popularization was largely due to the fashion world and the emergence of women's fashion magazines by the end of the 19th century and, since then, the appearance of fetish in style essays can be observed. But how frequently does that happen? What fetishist accessories and outfits are featured in the style essays of fashion magazines - in this analysis, the style essays of Vogue Brazil, between 2007 and 2011 and what poses and mannerisms are related to fetish in the photographs that make up the style essays? That is what our inquiry seeks to answer, associating numerical results to a qualitative breakdown of the images and to its present-day context, while inferring women's and men's roles from the mindset pictured in these images.
\end{abstract}

Keywords: Fetish; Fashion photography; Style essay; Vogue Brazil magazine; Gender representation. 
O fetiche está muito presente hoje em várias áreas do conhecimento e na mídia. Além disso, a sua relação com a moda não é recente, e já foi estudada e publicada anteriormente. A partir dessa relação já estabelecida, as revistas especializadas em moda passaram a utilizar e construir imagens que contêm referências ao fetiche, normalmente utilizando acessórios, vestuários, poses e trejeitos que remetem a alguma prática fetichista. Iremos analisar a frequência com que o fetiche é escolhido para ser representado nos editoriais de moda das revistas, principalmente de uma revista de alta circulação como a Vogue Brasil, e o que se pretende ao fazê-lo.

Nessa pesquisa, o fetiche está conceituado dentro da ótica psicanalítica, relacionado ao seu aspecto sexual. É importante entendermos que o fetiche, como patologia, é algo raro e pertencente a uma pequena parcela da população. A maioria das pessoas que se consideram de fato fetichistas, conseguem sê-lo sem que isso interfira diretamente na sua vida cotidiana, então, nesses casos, não poderemos considerá-lo uma patologia. Além disso, todos nós estamos sujeitos a um pouco de fetiche, sedução e erotismo na nossa vida privada.

O fetichismo apareceu como conceito relacionado às patologias sexuais pela primeira vez no livro de Krafft-Ebing, intitulado Psychopathia sexualis, primeira edição em 1886, em que são mostrados estudos de caso de pacientes com parafilias ${ }^{1}$. Foi KrafftEbing quem cunhou os termos "masoquismo" e "sadomasoquismo". Sua linguagem beira a poesia, mas seus tratamentos seriam hoje considerados antiquados, ultrapassados e até mesmo preconceituosos. Na obra, o fetichismo é considerado uma neurose cerebral e segue explicado como algo que:

\footnotetext{
1 De acordo com o DSM-IV (Diagnostic and Statistical Manual of Mental Disorder), "As características essenciais de uma parafilia são recorrentes e intensas fantasias sexualmente excitantes, impulsos sexuais ou comportamentos geralmente envolvendo 1) objetos não-humanos, 2) o sofrimento ou a humilhação de si mesmo ou do parceiro, ou 3) crianças ou outras pessoas sem o consentimento delas, que ocorrem ao longo de um período de pelo menos 6 meses (Critério A). Para alguns indivíduos, as fantasias ou estímulos parafílicos são obrigatórios para a excitação erótica e sempre incluídos na atividade sexual". Tradução da autora de: "the essential features of a Paraphilia are recurrent, intense sexually arousing fantasies, sexual urges, or behaviors generally involving 1) nonhuman objects, 2) the suffering or humiliation of oneself or one's partner, or 3) children or other nonconsenting persons that occur over a period of at least 6 months (Criterion A). For some individuals, paraphilic fantasies or stimuli are obligatory for erotic arousal and are always included in sexual activity" (American Psychiatric Association. Diagnostic and statistical manual of mental disorders. 4. ed. Washington: American Psychiatric Assoc, 2000).
} 
(...) investe de sensações voluptuosas a representação imaginária de partes isoladas do corpo ou peças do vestuário do sexo oposto, ou até mesmo simples pedaços de pano. (...) Em geral, quando o fetiche está ausente, o coito se torna impossível ou só pode ser realizado sob a influência da respectiva representação imaginária, podendo, mesmo assim, não trazer satisfação. (KRAFFT-EBBING, 2000, p. 8)

É importante ressaltar que as análises de Krafft-Ebing foram pioneiras e são um retrato de sua época (final do século XIX), momento em que a repressão sexual ainda era evidente. Seu julgamento moral aparece de forma clara em seu texto. Ele acreditava que a abstinência do desejo, a erradicação do comportamento parafílico ou até mesmo a hidroterapia (banhos com amarras em banheiras) e a faradização (forma inicial do eletrochoque) eram a cura para as psicopatias sexuais, incluindo o fetichismo (SELLERS, 2000, p. 9-10).

Em 1887, um ano depois de Krafft-Ebing, Alfred Binet (1857-1911) utilizou o termo "fetichismo" no ensaio Le Fetishisme dans l'amour pela primeira vez com uma conotação e um sentido psicológicos. O autor explica que a obsessão do fetichista atém-se a objetos inanimados, que são a causa do desejo e do prazer sexual, exceto em alguns casos verificados naquele momento como novidade - de uma obsessão por partes do corpo não comumente detentoras de provocarem desejo sexual. Dentro do que ele chama de “fetichista em amor" (fétichiste en amour), Binet afirma que todos o somos mais ou menos; e que "há uma dose constante de fetichismo no amor mais comum"” (BINET, 1888, p. 144).

Outro aspecto relevante do fetichismo é que normalmente ele aparece como uma parafilia predominantemente masculina:

Depois de estudar fantasias eróticas e comportamento sexual por muitos anos, o psiquiatra Robert Stoller concluiu que "fetichizar é a norma para homens, não para mulheres". Isso não quer dizer que as mulheres não se interessem por partes do corpo ou roupas sensuais. Mas elas não parecem "desejá-las ardentemente" da mesma forma que os homens o

2 Tradução da autora de "il y a une dose constante de fétichisme dans l'amour le plus régulier". 
fazem. (Essa é uma questão importante se queremos explorar o apelo para as mulheres de roupas que os homens tratam como fetiches). (STEELE, 1997, p. 20)

A explicação mais comum para esse fato é o conceito elaborado por Sigmund Freud, primeiramente na obra Três Ensaios sobre a Teoria da Sexualidade, de 1905, e, mais tarde, no artigo Fetichismo de 1927, no qual:

(...) o fetiche, na verdade, é um substituto para o pênis. (...) trata-se de um pênis que em casos normais deveria ter sido abandonado ao longo do desenvolvimento, mas que o fetiche tem a função de preservar. (...) o fetiche é um substituto do pênis da mulher (da mãe) em que o menininho outrora acreditou e do qual - bem sabemos o porquê - não quer de modo algum abdicar. (FREUD, 2007, p. 162)

No caso, Freud refere-se à castração e ao medo que o menino tem da castração. Quando o menino percebe que sua mãe não possui pênis, sente que o próprio pênis está em perigo, então consegue um substituto para o falo "perdido" da mãe (FREUD, 2007). Nesse caso, o falo é um símbolo, estamos nos referindo a um falo simbólico.

Jacques Lacan (1901-1981), psicanalista freudiano e importante figura na corrente de pensamento conhecida como Estruturalismo, explana sobre o objeto de fetiche n'O Seminário, livro 4, quando disserta sobre a relação de objeto.

Lacan nos informa sobre como o fetiche trabalha na instância do simbólico, e como, justamente por isso, alguns autores afirmam que o fetichismo situa-se no limite entre a neurose e a perversão. Ele mostra o "Esquema do Véu”, cuja importância reside em conseguirmos situar corretamente os elementos que entram em jogo na instauração da relação fetichista. Esse esquema mostra que “com a presença da cortina, aquilo que está mais além, como falta, tende a se realizar como imagem. Sobre o véu, pinta-se a ausência” (LACAN, 1995, p. 157). Então, o objeto assume o lugar dessa ausência. 


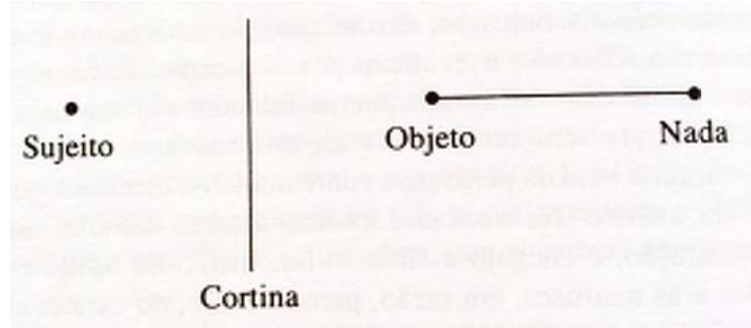

Figura 1. Esquema do Véu, por Lacan³.

Sendo o fetiche, então, ligado ao simbólico, à fantasia e ao imaginário, não é de se espantar que a moda aproprie-se dele para representar o desejo, a luxúria, o glamour. Ainda, a mulher, na publicidade e na moda, tem a função de objeto e assim torna-se fetiche também.

A fotografia de moda possui uma peculiaridade que a difere de outros gêneros da fotografia, que é a sua relação com a publicidade e com o consumo. E é por este motivo que ela foi escolhida para esta pesquisa: em seu núcleo, encontramos aspectos tão diversamente relacionados - como a relação entre imagem e consumo; e sua capacidade de criar sonhos e fantasias - quanto a própria comunicação.

A partir dos anos 1960 e com o movimento de "liberação sexual" 4 feminino, o que antes era considerado algo a ser escondido passou a ser revelado. Nesse momento, a imagem fetichista habitava, em sua maior parte, as revistas sobre sexo e a moda fetichista era difícil de ser adquirida. Foi justamente a partir de publicações sobre sexo que o fetichismo começou a se mostrar e o movimento de "liberação sexual" serviu para que, o que antes era considerado perverso, começasse a ser sedutor (STEELE, 1997).

Na moda moderna, a sedução é um fator primordial para que haja um mercado consumidor, e é nela (moda) que ela (sedução) se apoia todo o tempo. A fotografia de

\footnotetext{
3 Imagem disponível em: LACAN, Jacques. O Seminário, livro 4: a relação de objeto. Rio de Janeiro: Jorge Zahar Ed., 1995, p. 158.

4 Movimento que se iniciou nos anos 50 com a publicação do livro O Segundo Sexo, de Simone de Beauvoir, e que continua com a "queima" dos sutiãs de ativistas do grupo WLM (Women's Liberation Movement) nos Estados Unidos, em protesto contra o concurso de Miss America em 1968, e com o surgimento da pílula anticoncepcional. (FREEMAN, Jo. Sem data. disponível em: http://www.jofreeman.com/photos/MissAm1969.html. Acesso em: 28 fev. 2013).
} 
moda é parte presente e constitutiva no imaginário multilocalizado mencionado por Néstor García Canclini em sua obra Consumidores e Cidadãos: conflitos multiculturais da globalização (1995), um meio de produzir representações e ajudar na formação de identidades: a cultura de massa e a velocidade da comunicação permitem que os consumidores populares interpretem o imaginário multilocalizado que a televisão e a publicidade reúnem - são ídolos de cinema hollywoodiano e da música pop, logotipos de jeans e cartões de crédito, atletas de esportes do mundo todo, personagens de desenhos animados, refrigerantes, entre outros, que compõem um "repertório de signos constantemente disponível” (CANCLINI, 1995, p. 63).

Inicialmente, a fotografia de moda tem a função de documentar o vestuário para depois passar a ter uma função ficcional, de produto do imaginário, de fantasia (FEREZ, 1999; QUIROS, 1993; RUHRBERG; WALTHER, 2000 apud SILVA, 2007, p. 44). A fotografia de moda, então, passa a querer contar uma história e faz isso pelo processo de associação de ideias (BARTHES, 1979, p. 285). A moda, nesse caso, "tenta manifestar associações de substâncias, estabelecer equivalências plásticas ou sinestésicas" (BARTHES, 1979, p. 285-286). Ela evolui da simples documentação para a criação. Segundo Mabel Ferez, "o fotógrafo de moda traz o mundo para perto de si, em vez de ir ao mundo. Seja no estúdio, seja em locações, seu trabalho não existe sem intenções - ele inventa o universo a ser fotografado" (1999, p. 3).

Alexandre Liberman, diretor de arte e, mais tarde, diretor geral da Condé Nast Publications, defendia incisivamente o que uma mulher espera ver em uma fotografia de moda: "[...] um espelho de si, de suas fantasias, de como ela quer ser vista pelos outros, de quais roupas ela pode usar e como ela pode usá-las"'5 (ANGELETTI e OLIVA, 2012, p. 56).

Então, no aspecto ficcional da fotografia de moda, podemos incluir o fetiche como um elemento que pode despertar a imaginação e o desejo do leitor. O desejo dentro da publicidade surge como algo típico, pois é ele o responsável pelo seu impulso de compra. A troca de objetos efetivada pelos indivíduos na sociedade é o que media todas as

5 Tradução livre da autora de: "a mirror of herself, of her fantasies, of how she wants to be seen by others, of what clothes she can wear and how she can wear them". 
relações humanas (KEHL, 2004 apud RAMOS, 2006), sendo que esses objetos são completos de significados, "culturalmente e socialmente adequados e favoráveis" (RAMOS, 2006, p. 29). Logo, o que é desejado não é o objeto a ser comprado, mas sim algo que possa suprir uma carência, tanto pessoal quanto social (VESTERGAARD; SCHRODER, 2004 apud RAMOS, 2006), que jamais será suprida, como já dito anteriormente. É nesse espaço que a publicidade age, nos fornecendo objetos que são promessas de sucesso e de satisfação garantida (RAMOS, 2004).

Os objetos a serem desejados são lançados pelos meios de comunicação (RAMOS, 2004). Guy Debord (1931-1994) em A Sociedade do Espetáculo, afirma que as revistas femininas mostram o estilo mais favorável para o mercado, os lugares da moda (DEBORD, 2004). As pessoas devem adequar-se ao que é oferecido no mercado, pois a indústria não pode produzir um produto para cada indivíduo da sociedade, então, com isso se busca encaixar-se no modelo pré-determinado, na imagem mais próxima daquela pessoal e individual do sujeito, distanciando-se este do que realmente é e aproximando-se do que foi criado pelo Outro (RAMOS, 2004). Tomás Moulian (1939), sociólogo e professor universitário chileno fala sobre a transformação do consumo em gozo. Ele explica que essa transformação não só realiza uma necessidade do sistema, mas também do indivíduo, e que "os objetos contribuem para a realização das possibilidades do eu" (MOULIAN, 1999 apud BUSATO, 2001, p. 164).

Ao final dos anos 1970, a fotografia de moda é "uma operação sutil e complexa que envolve arte, talento, técnica, psicologia e vendas", como descreveu Alexander Liberman, diretor editorial da revista Vogue na época (BROWN, 2012, p. 488). A mulher surge como uma figura poderosa, e tanto a moda quanto a fotografia tornaram-se aspectos obrigatórios no cotidiano da sociedade. Fotógrafos como Helmut Newton (1920-2004), Guy Bourdin (1928-1991), Gian Paolo Barbieri (1938) e Chris von Wangenheim (1942-1981) retrataram o mundo da moda como sendo de luxo, fantasia e consumo (BROWN, 2012).

Algo que precisa ficar claro é a diferença entre o fetichismo e o "erotismo com roupas" (STEELE, 1997). O fetiche objetifica a mulher e sensualiza os objetos, faz com que os acessórios da moda sejam eles em si desejados, e não apenas a imagem de uma 
mulher usando uma vestimenta sensual. O fetiche tem a ver com a fantasia, com o imaginário que foi criado para todos os objetos e roupas que o senso comum enxerga como fetiche, e aqueles que são utilizados de fato por quem o pratica sexualmente. $\mathrm{O}$ fetiche, na fotografia de moda, passa mais pelo imaginário que a sua popularização trouxe do que pela perversão, estigmatizada pela psicanálise por Krafft-Ebing, Freud, Lacan, e outros. Ele tornou-se símbolo de luxo e glamour na fotografia de moda, e brinca - nos editoriais de moda - com conceitos de submissão, dominação, poder e nudez. Surge, então, um questionamento a respeito de como as mulheres respondem às imagens da moda, aos fetiches mostrados para serem consumidos por elas próprias com a função de saciar o desejo do parceiro, na maioria dos casos. A mulher, nesse exemplo, torna-se o próprio fetiche, o objeto de desejo. E quem é que não quer ser desejada dentro dos moldes permitidos e ovacionados pela sociedade?

Então, se o fetiche é um desejo causado por uma castração, como Freud defendeu, ou pelo medo dela, e a publicidade trabalha justamente com o desejo de preencher uma falta, a publicidade pode utilizar, com sucesso, o fetiche nas fotografias publicitárias de moda para atingir o objetivo final de provocar o desejo de consumir, principalmente nas mulheres que compram as revistas femininas de moda e que buscam tornar-se um objeto de desejo (sexual).

A revista Vogue teve a sua primeira edição em 1892, em Nova lorque, por Arthur Baldwin Turnure. O periódico semanal surgiu para representar os interesses e estilo de vida da alta classe nova-iorquina, que, nessa época, surgia como uma burguesia ávida por consumir. Esse primeiro número incluiu artigos sobre moda para homens e mulheres, resenhas de livros recentemente publicados, teatro, música e artes, e um grande número de matérias sobre etiqueta e sobre como se comportar em eventos sociais (ANGELETTI; OLIVA, 2012).

Em 1909, Condé Montrose Nast, um jovem advogado e jornalista, comprou a Vogue com a intenção de transformá-la "na mais fabulosa revista de estilo e moda em qualquer lugar, sempre."6 (ANGELETTI; OLIVA, 2012, p. 2). Com a sua editora - Condé Nast

6 Tradução livre da autora de: "(...) into the most fabulous magazine of style and fashion culture anywhere, ever." 
Publications -, a revista passou a ser editada duas vezes por mês, mais cores foram adicionadas às capas, mais páginas foram alocadas para publicidade e mais artigos sobre sociedade e moda foram escritos. Tornou-se, por fim, uma publicação feminina. (ANGELETTI; OLIVA; WINTOUR, 2012).

A Vogue abrigou os primeiros fotógrafos de moda e, com isso, fez história. Não só contratou fotógrafos exclusivos, como construiu grandes estúdios muito bem equipados. Mas os fotógrafos - Horst, Beaton, Steichen ou Hoyningen-Huené - sofreram todas as duras críticas de Condé Nast. A empresa mantinha o hábito de analisar detalhadamente todas as fotografias e encontrar seus defeitos, sob a justificativa de que seus fotógrafos compartilhavam de uma propensa liberdade artística e criativa em excesso, o que ia contra o imperativo em uma revista de moda em retratar não apenas belas mulheres em belas roupas, mas todos os detalhes de como a roupa foi construída e usada, para que o leitor pudesse copiá-la (ANGELETTI e OLIVA, 2012).

A edição brasileira da revista Vogue - conhecida como Vogue Brasil - teve o seu primeiro número “(...) publicado pela Editora Três, em maio de 1975. (VIANA, 2000 apud NOVELLI, 2009, p. 96-97). Nos seus quase 40 anos de existência, a Vogue Brasil tem a tradição de publicar editoriais inéditos, de fotógrafos brasileiros e com modelos brasileiras. Normalmente, um editorial internacional que já foi publicado em outra edição internacional da Vogue (chamado de "re-print") também é publicado. São publicados entre 3 e 6 editoriais por número, sendo esses os analisados durante a pesquisa.

Para a coleta de dados aqui representada ${ }^{7}$, foram analisados 59 números da revista Vogue Brasil. O primeiro número foi o $n^{\circ} 341$, de janeiro de 2007, e o último foi o $n^{\circ}$ 400, de dezembro de 2011. Os editoriais analisados foram 247, e eles se localizam, na revista, logo após o texto editorial intitulado "Ponto de Vista", no qual o editor-chefe explica um pouco a escolha dos editoriais e qual é a tendência da moda presente neles. Em alguns momentos, o nome das modelos é mencionado nesse texto, em outros não

\footnotetext{
7 Dados da pesquisa de mestrado aprovada e disponível na Biblioteca Central da Universidade de Brasília: OUROFINO, A. G. DE. O Fetiche na Fotografia de Moda: editoriais da revista Vogue Brasil de 2007 a 2011. 161 p. Dissertação (Mestrado em Comunicação) - Programa de Pós-Graduação da Faculdade de Comunicação da Universidade de Brasília (UnB). Brasília, março de 2013.
} 
(modelos masculinos nunca são mencionados). Na maioria das vezes, o nome do fotógrafo é mencionado. A análise considerou o número de imagens, e não de páginas, em cada editorial. Do total de 247 editoriais analisados, foi encontrada a participação de 323 modelos femininos e 41 modelos masculinos. Os itens analisados foram definidos de acordo com a pesquisa sobre o que é o fetiche e com base na leitura do Dicionário de Fetiches e BDSM (SHAKTI, 2008).

Os números encontrados, traduzidos em porcentagens, nos levam ao seguinte resultado:

\section{Frequência de modelos nos editoriais - porcentagem}

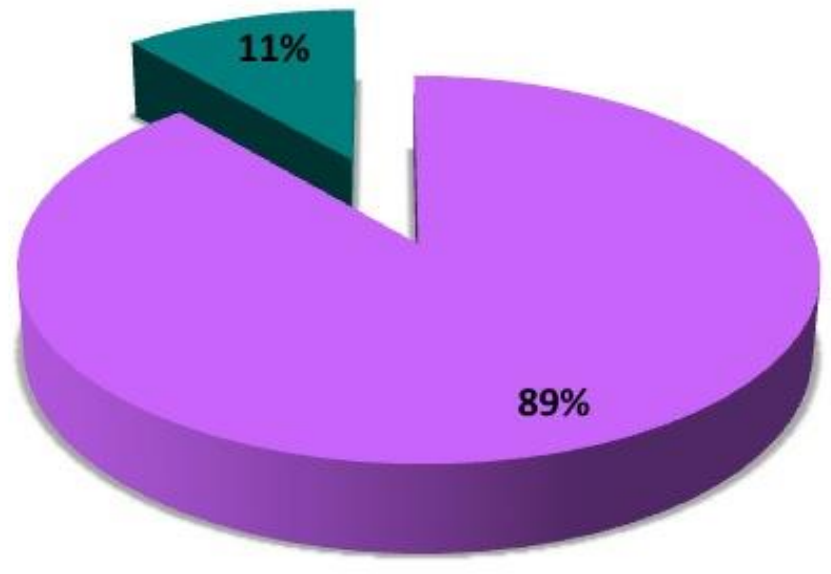

Modelos femininas

Modelos masculinos

Figura 2. Gráfico de frequência de modelos masculinos e femininos da pesquisa. 


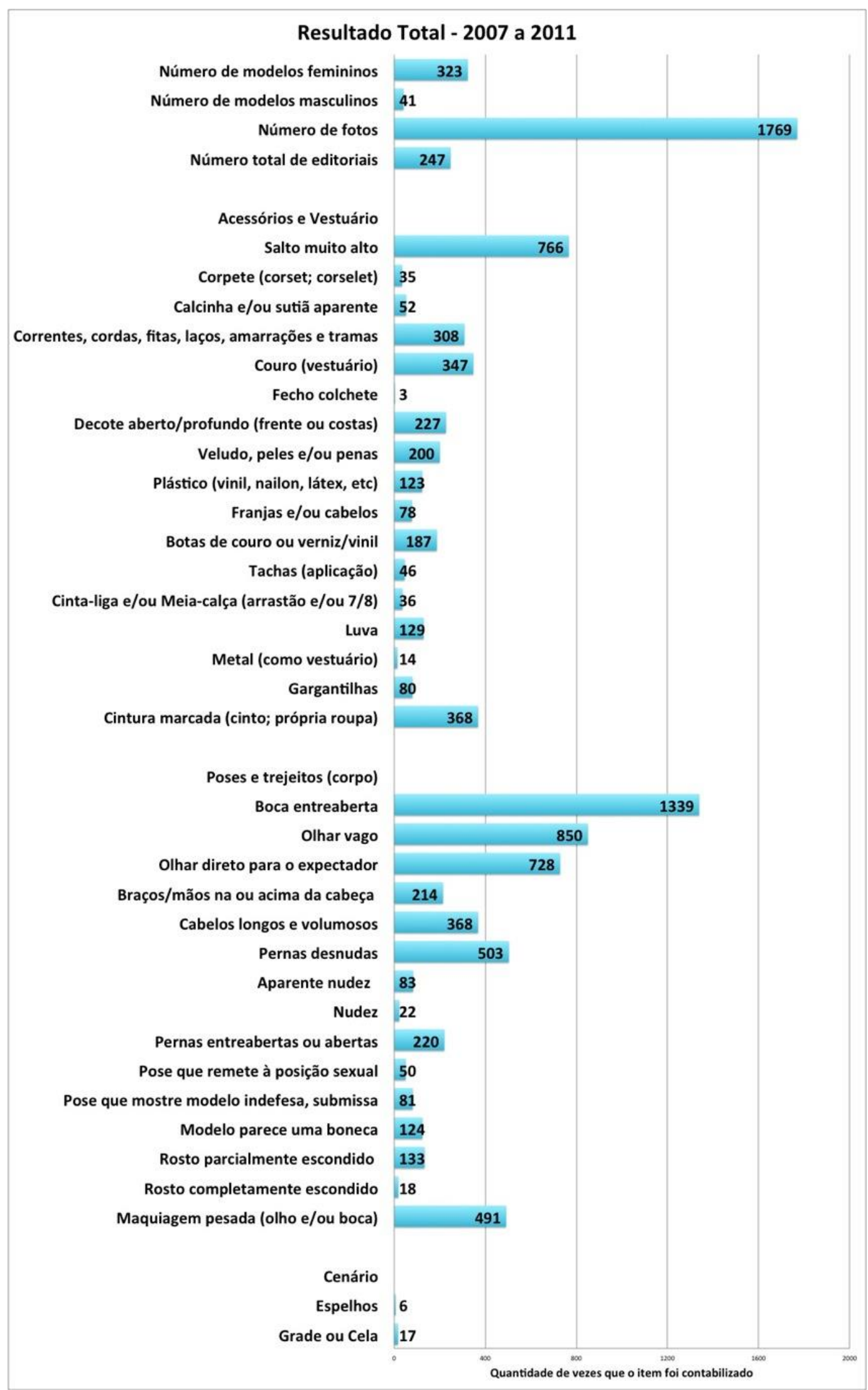

Figura 3. Gráfico com a frequência total de todos os itens analisados na pesquisa. 
A recepção da imagem, a sua interpretação e até mesmo a sua compreensão não podem ser consideradas universais, pois devemos considerar que "existem, para a humanidade inteira, alguns esquemas mentais e representativos universais, arquétipos ligados à experiência comum a todos os homens" (JOLY, 2010, p. 42), mas não todos, e não da mesma forma para todos os seres humanos. Principalmente, a interpretação é algo que foge, por exemplo, ao emissor da mensagem, pois a imagem pode ter significados completamente diferentes para um e para outro receptor. Como analista de imagem, pretendo decifrar as significações dessa "naturalidade" nas fotografias de moda dos editoriais da revista Vogue Brasil. Em termos metodológicos, como analista, me coloco do lado em que estou de fato, ou seja, como receptora da mensagem daquela imagem, sem me livrar, no entanto, da necessidade de estudar o histórico dessa mensagem (tanto a emissão quanto a sua recepção). Isto posto, seguimos com a análise da presença do fetiche nos editoriais referidos.

Ao analisar todas essas imagens da Revista Vogue Brasil, de 2007 a 2011, percebemos que o fetiche aparece não apenas de maneira tradicional - como os acessórios e o vestuário em si - mas também de maneiras simbólicas e mais leves, sem a carga de bizarro e de perversão que normalmente o acompanham quando ele é tratado fora do seu meio.

A partir do gráfico sobre o número de modelos femininos e masculinos encontrados nos editoriais (Figura 2), podemos perceber que, nos editoriais de moda da Revista Vogue Brasil no período analisado, o número de modelos femininos que posaram para as fotos foi de $89 \%$ e o de modelos masculinos foi de apenas $11 \%$. Isso demonstra que as mulheres são o principal gênero presente nessas imagens. É curioso pensar que a maioria dos modelos é mulher, dentro de uma revista feminina, e que dentro das revistas masculinas nós também encontramos grande quantidade de imagens de mulheres (ainda mais se for uma revista de conteúdo sexual). Essa é uma percepção própria, e não foi baseada em nenhum dado de pesquisa, por ora. A mulher então aparece como imagem, seja para a própria mulher, seja para o homem.

O papel do modelo masculino nas imagens analisadas é sempre um papel secundário. O homem é um acessório, um acompanhante, ou uma figura que apoia 
qualquer que seja a ação da mulher na imagem, frequentemente uma imagem bastante fetichista, presente na relação de dominação e submissão. Ele aparece completamente vestido, usando ternos ou vestuários que cobrem o corpo todo, ou então apenas cueca ou calça, deixando o torso à mostra. O homem aparece aqui também como um objeto de desejo dessas mulheres, mas em pouca frequência, e só é identificado por legenda se já for uma pessoa conhecida, famosa.

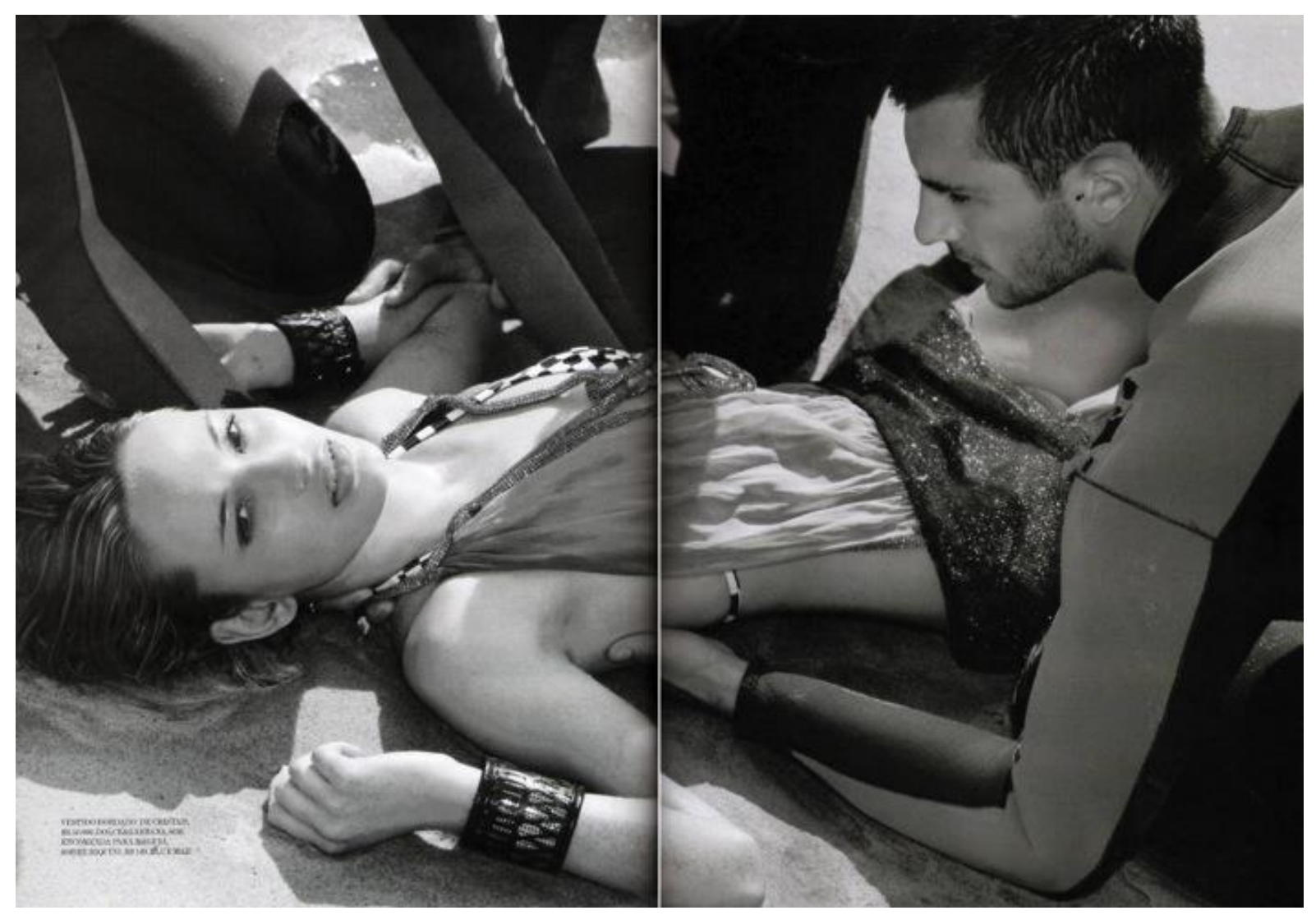

Figura 4. Vogue Brasil de nov. 2007, n. ${ }^{\circ}$ 351, editorial O Resgate do Hi-Lo. 


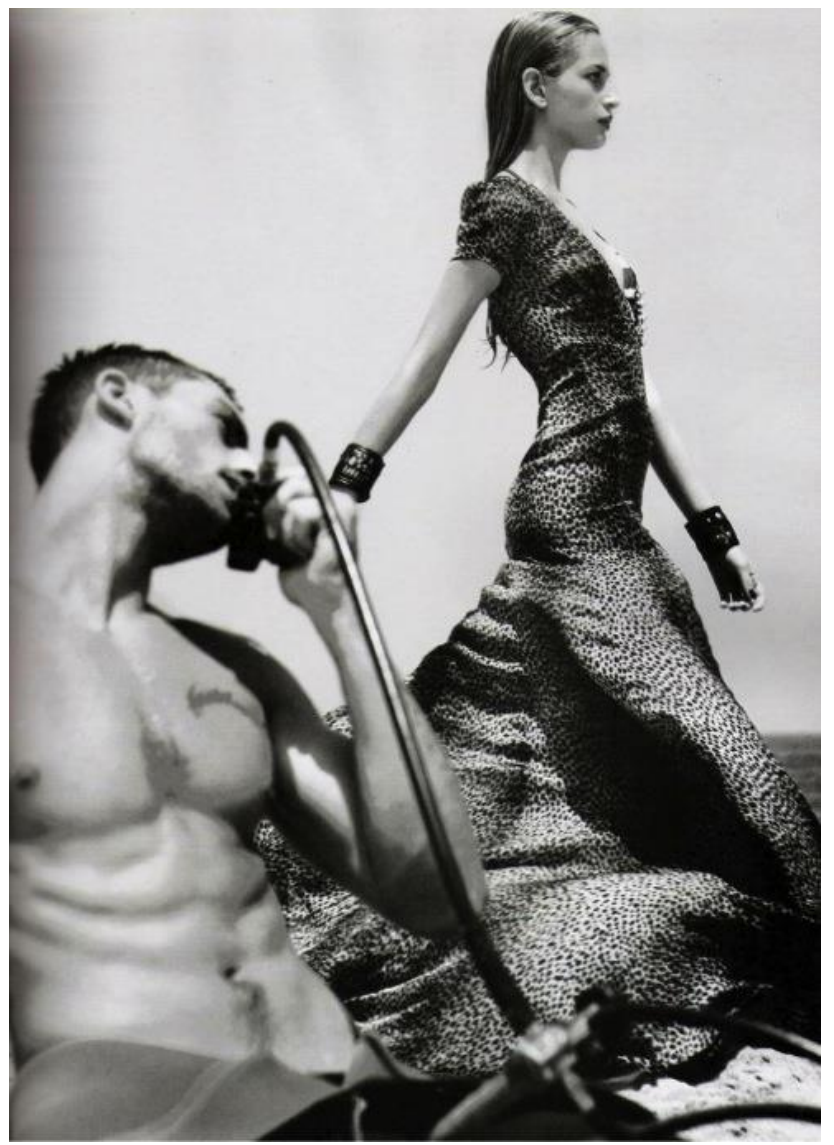

Figura 5. Vogue Brasil de nov. 2007, n. ${ }^{\circ}$ 351, editorial O Resgate do Hi-Lo.

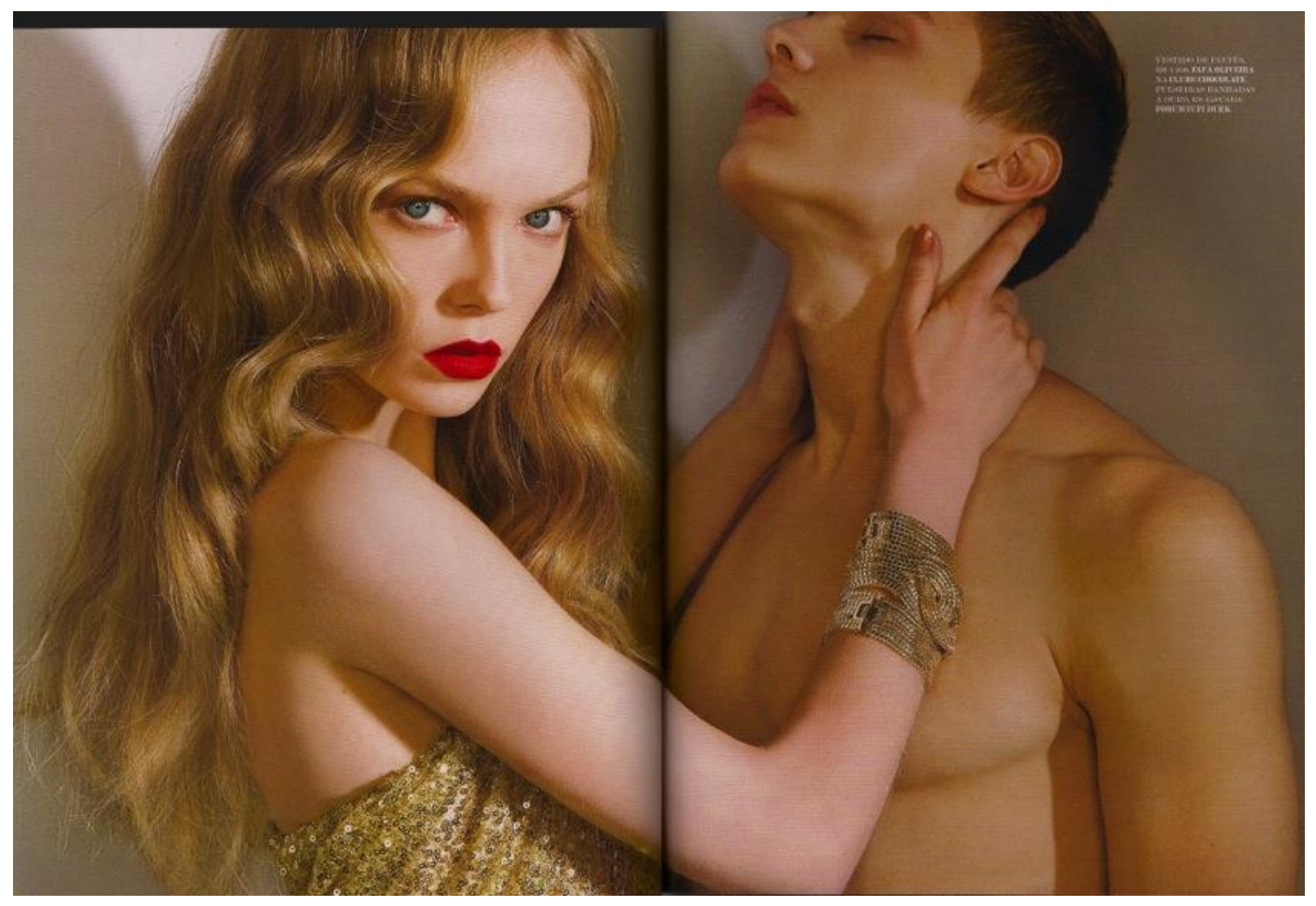

Figura 6. Vogue Brasil de dez. 2008, n. ${ }^{\circ} 364$, Dama de Ouros. 
O item mais frequente da lista de acessórios e vestuários, nos editoriais da revista Vogue Brasil de 2007 a 2011, foi o salto alto, muito alto, de $10 \mathrm{~cm}$ ou mais. Do total de 1.796 imagens que foram analisadas, 43,3\% delas contêm um salto muito alto. Mesmo para quem não tem fetiche com sapatos ou pés, o salto alto é um símbolo de poder, de dominação. A mulher que usa um salto muito alto, não apenas fica mais alta de fato, como assume uma posição de ser vista de baixo, uma posição de superioridade. Nesse sentido, entra em forma a fantasia da dominação, e a mulher é poderosa e dominante, enquanto o homem é o escravo e submisso. "Calçado com um sapato de salto alto, 'o pé se torna uma arma misteriosa que ameaça o homem passivo; e ele se envaidece de ser assim conquistado'. O sapato de salto alto é um 'símbolo de amor'- e também 'um símbolo de agressão", como declarou a revista High Heels, em 1962 (STEELE, 1997, p. 108). Por outro lado, o sapato muito alto é uma forma de limitação, pois é muito difícil caminhar com esses calçados, porém, eles atribuem ao andar uma delicadeza e elegância que não vemos no uso de outros tipos de sapatos, e nesse sentido, usar o salto pode ser uma forma de masoquismo, como aquele que acontece ao utilizar um corselet muito apertado.

A forma que o corpo adquire quando a mulher está usando salto alto é muito erótica para muitos homens, pois as pernas ficam torneadas e o quadril fica arqueado, sem contar que a coluna precisa ficar ereta para poder caminhar sem cair. Vemos nos editoriais alguns sapatos muito mais altos do que poderíamos ver disponíveis para o consumidor comum, e isso reforça a imagem de que aquela modelo, naquela revista, é uma mulher cuja imagem deve inspirar. As mulheres que consomem as imagens dos editoriais buscam não apenas a moda e as tendências da moda, mas uma inspiração de qual mulher ser, de qual papel assumir. Nas imagens em que sapatos de salto alto são utilizados, ainda mais os muito altos, a mensagem transmitida é de poder.

As botas (10,6\%) - de couro, de vinil, de verniz - diferenciam-se dos saltos altos, pois possuem uma parte da perna em si. Seja de cano mais curto ou de cano longo, cobrindo até as coxas, as botas são um acessório típico da Dominatrix e estão associadas ao jogo de dominação e submissão juntamente com o vestuário em couro (19,6\%) e com qualquer acessório e vestuário de látex ou vinil (7\%). Essa frequência de 7\% dos acessórios 
de plástico (látex, vinil, náilon) é alta, se lembrarmos que não é comum no nossos cotidiano usarmos esse tipo de material. As botas são um acessório masculino, que vieram do trabalho do construtor, do pedreiro, do engenheiro, do vaqueiro, etc., e que estão associadas ao falo também por causa da sua forma. "Botas também têm sido associadas a lésbicas. No Brasil contemporâneo, a palavra usada para definir uma lésbica é sapatão, que quer dizer literalmente 'sapato grande"' (STEELE, 1997, p. 111). As botas são, então, sinônimo de poder e de masculinidade, e já fazem parte da moda como um acessório sempre presente - nas coleções de outono/inverno principalmente - e hoje são usadas com saias, vestidos ou até mesmo por cima das calças.

A cintura marcada, seja por um cinto ou pelo modelo da própria roupa, é o segundo item mais frequente, aparecendo em 20,8\% das imagens. Foram contabilizadas aqui apenas imagens em que a cintura estava bem marcada, ou seja, casos em que apenas havia um cinto no cós da calça não foram contabilizados. Isso demonstra que o conceito de forma do corpo feminino, que foi muito comum no século XIX, continua presente de alguma forma. A ideia que temos é que o corpo fica mais feminino ao marcarmos a cintura, tal qual faziam as mulheres com os corselets bem amarrados para, em seguida, colocarem uma saia volumosa ou um vestido e ficarem, ainda assim, com a cintura fina. Essa forma do corpo é conhecida como ampulheta e, hoje, a maneira mais fácil de reproduzi-la é usando cintos ou a própria modelagem da roupa. A jornalista Mônica Salgado cita na página da revista Vogue Brasil na internet ${ }^{8}$, a respeito de um desfile da São Paulo Fashion Week para o verão 2012, que aconteceu em junho de 2011, que: "Peçadesejo: a calça capri 50's de cintura alta; É tendência: corselets e construções inspiradas neles adicionam leve pitada de fetiche e elegem novo ponto focal da silhueta, os seios". Ou seja, não apenas a cintura alta é uma "peça-desejo", como os corselets aparecem para criar um ar fetichista - e assim, sensual - ao vestuário, sendo um acessório típico para marcar a cintura, valorizar a forma ampulheta do corpo e realçar os seios da mulher.

As gargantilhas, com frequência de $4,5 \%$, são aquelas que marcam o pescoço, algumas a ponto de parecer que estão enforcando a mulher, e que podem ser associadas à prática de Asfixiofilia ou Hipoxifilia. É diferente de quando a mulher usa um lenço ou um

8 Artigo disponível em: http://revista.vogue.globo.com/desfiles/marca-estilista/herchcovitch-sao-pauloverao-2012/. Acesso em: 28 fev 2013. 
cachecol no pescoço, pois nesse caso parece que ela quer esconder essa parte ou protegê-la, o que não acontece ao usar a gargantilha.

É interessante o aparecimento de 7,3\% de luvas nos editoriais da Vogue que foram analisados. As luvas, na área da saúde, atuam como proteção para o corpo, assim como em outras áreas profissionais como aquelas que fazem uso de equipamentos pesados e cortantes, jardineiros; e no esporte - luvas de boxe, de goleiro, de esgrima e de beisebol. Elas têm a função de proteger as mãos do frio, nos países onde o inverno é muito intenso, mas aparece com essa frequência relativamente alta em uma revista que é veiculada em um país tropical, que não possui inverno com temperaturas muito baixas que exijam o seu uso. As luvas compõem o visual da mulher dominadora - juntamente com o chicote, o salto ou bota, a calça ou macacão de látex ou de couro, ou uma meia-calça arrastão com cinta-liga, dependendo da fantasia das pessoas envolvidas -, principalmente as que preenchem todo o antebraço e são de vinil ou verniz. Luvas também fazem parte de um visual chique de noite, com vestidos longos, e nesse caso são de seda, cetim ou veludo. Nos editoriais, elas são usadas para compor o visual da mulher poderosa e glamourosa.

O corpo, a pele da mulher, é reverenciada com 12,8\% de decotes profundos, abertos - seja na frente ou nas costas - nas imagens dos editoriais; 4,7\% de nudez aparente (transparência, partes do corpo tampadas mesmo se nuas, à mostra por baixo da roupa, etc.); 1,2\% de nudez propriamente dita e 28,4\% de pernas desnudas (fendas; body; microssaias; saia transparente). Os editoriais que mostravam roupas de banho não foram contabilizados nesses dados, pois mostram o corpo como característica do próprio vestuário. As microssaias, os vestidos curtíssimos e os decotes foram muito encontrados, e levaram a perguntar: "mas será que a mulher comum, aquela que compra a revista para ler em casa, usa esse tipo de vestuário?". A ideia que o editorial pode querer passar é a de que a mulher não precisa ter vergonha do próprio corpo, e que a moda suporta e faz peças para que a nudez do corpo e da pele seja valorizada. Mas mesmo em pleno século XXI, o uso de microssaias e microvestidos pode causar problemas para a mulher que escolhe esse estilo, como é o caso da estudante Geisy Arruda, que, em outubro de 2009, foi perseguida nos corredores da faculdade Uniban, em que estudava, por usar um microvestido rosa. O linchamento verbal foi filmado e já estava na internet poucos 
momentos depois ${ }^{9}$. Após esse acontecimento, Geisy ficou famosa e hoje trabalha na televisão, tendo também conseguido uma indenização da Uniban no valor de R\$ 40 mil. Essa situação demonstra que ainda existe preconceito no Brasil quando a mulher mostra o seu corpo, mesmo que ela seja estimulada pelas revistas de moda - no caso, pela Vogue Brasil - a utilizar peças bem curtas e decotadas. Termina por ser considerada vulgar, promíscua, fácil e oferecida - adjetivos utilizados contra a estudante supracitada.

A boca entreaberta, característica tão própria das fotografias de moda, dá um aspecto blasé ao rosto da modelo. Dependendo de como é o seu olhar - olhar vago ou encarando o espectador - essa boca entreaberta pode ser algo sensual e submisso, ou algo poderoso e que distancia a modelo, tornando-a um objeto de desejo. As modelos hoje, inclusive, podem ser consideradas objetos de desejo assim como as roupas que vestem nos editoriais, pois tornam-se muito conhecidas pelo público e verdadeiras celebridades do mundo da moda.

O olhar vago das modelos apareceu em maior frequência nessa análise (48\%) do que o olhar direto para o expectador (41,2\%). Esse olhar vago é aquele que mostra a modelo como inalcançável, como distante e poderosa, mas não de uma maneira impositiva. Quando a modelo encara o expectador, é como se ela o desejasse, como se chamasse - e dependendo de como estão a boca e o figurino - se posicionasse de maneira sensual. Nesse caso, nós temos tanto o papel da mocinha indefesa, inalcançável e submissa, quanto o papel da mulher poderosa, independente e que corre atrás do que deseja.

Com uma frequência de $2,8 \%$, as modelos se encontram em uma posição que remete à sexual. Nessas imagens, é como se a modelo estivesse entregue, pronta para promover o ato, e isso desperta o desejo de consumi-la, ou o desejo de estar fazendo a mesma pose. O sexo, na publicidade, é usado como atrativo para o consumo, e aqui não é diferente. Mas nos editoriais, há papéis sendo descritos, atitudes sendo sugeridas, e o

\footnotetext{
9 Informações nos artigos: MONTEIRO, André. Jovem hostilizada na Uniban quer recuperar "vida normal", disponível em http://www1.folha.uol.com.br/folha/educacao/ult305u647258.shtml. Acesso em: 03 mar. 2013. Sem autor; TJ mantém indenização de R\$ $\mathbf{4 0}$ mil da Uniban para Geisy Arruda. Disponível em: http://www1.folha.uol.com.br/cotidiano/1060927-tj-mantem-indenizacao-de-r-40-mil-da-uniban-para-geisyarruda.shtml. Acesso em: 03 mar. 2013.
} 
fato de que 50 poses - em 1769 imagens - remeteram a poses sexuais, sugere que a mulher está sendo incentivada a ter uma postura mais sexual na sua identidade, no seu vestir e na maneira com que se comportará quando quiser seguir aquilo que é chamado de "chique e glamouroso" pela mídia.

O cenário dos editoriais não foi amplamente analisado. Apenas verificou-se a existência de dois itens: espelhos e grade ou cela. Esses itens estão relacionados a fetiches e fantasias sadomasoquistas, mas tiveram uma frequência baixa nas imagens analisadas. Os cenários dos editoriais da revista Vogue costumam ser um lugar de fantasia, uma paisagem surrealista, e comumente pedem que abstraiamos da realidade para entendê-los.

A maquiagem pesada e bem marcada aparece em 27,7\% das imagens, e pode agir como um enaltecedor da boca e/ou dos olhos, sendo que a mulher que usa maquiagem muito pesada, muitas vezes, é considerada como promíscua ou fácil. A maquiagem é uma ferramenta que usamos como máscara para a nossa pele limpa e nua, e também para adornar e exaltar. O problema reside no fato de haver mulheres, hoje, que não gostam de si mesmas sem o adorno da maquiagem, e isso demonstra um problema de autoestima decorrente da falta de identidade contemporânea. A maquiagem também funciona como forma de incorporar um personagem, de criar uma boneca, e isso faz parte das fantasias. Aliás, em $7 \%$ das fotografias a modelo se parece com uma boneca, e nesse caso, ela representa um objeto inanimado, que retrata a submissão em um grau profundo. Caso a modelo esteja com a boca aberta, em formato oval, faz referência às bonecas infláveis, artigo sexual muito utilizado por homens, muitos por fetiche mesmo.

Pelo rosto é que mostramos a nossa expressão final, seja qual for o sentimento, e por onde mostramos nossa alma (através dos olhos) e nos fazemos ouvir (através da nossa boca/voz). Ao esconder o rosto (1\%) ou simplesmente retirá-lo da imagem, a identidade some e resta apenas o corpo, um objeto sem vida. Ao escondermos parcialmente o rosto (7,5\%), no entanto, o que se apresenta é um ar de mistério, em que a proposta é a de verificarmos o que há além daquilo que permanece escondido. Essa é uma mulher que habita o imaginário masculino e feminino: no caso do imaginário masculino, é a mulher que ele deve desejar, descobrir, ir atrás; no caso do imaginário 
feminino, é a mulher que ela deve ser, independentemente do seu desejo pessoal, ela deve manter o mistério para ser desejada, e ser difícil e inalcançável para não ser considerada vulgar e promíscua.

Em todos esses 59 exemplares da revista Vogue Brasil, 247 editoriais, 1769 fotografias, não houve nenhuma mudança significativa em termos de estilo ou de moda. As imagens são muito parecidas e massificadas, com modelos e fotógrafos recorrentes. A moda parece ter atingido um patamar no qual tudo é possível, e não há restrições para a mistura de estilos, cores, formas.

A partir da análise dos dados encontrados nessa pesquisa, fica claro que a hipótese inicial de que o fetiche está presente como uma estética atual nos editoriais da revista Vogue Brasil é verdadeira. Não apenas o "sexo vende", mas o fetiche popularizouse a tal ponto que já faz parte de uma estética cultuada pelo mundo fashion, inserido no contexto de glamour e luxo da alta moda.

O fetiche atua não apenas como estética, mas sugere uma postura a ser copiada pelo público feminino que consome a revista Vogue Brasil. Sugere, entre as variadas possibilidades de identidade que nos são ofertadas diariamente, que a mulher aja com confiança, poder e sensualidade; sugere que a mulher aja como uma mulher submissa, inalcançável e desejável. Sugere que a sensualidade da mulher está diretamente ligada ao tamanho do seu salto alto e à maneira com que utiliza os acessórios e vestuário da moda. A liberdade sexual alcançada hoje também permite que a mulher utilize a estética fetichista ao seu favor e como autoafirmação.

O homem, nessas fotografias, age apenas como coadjuvante. O gênero predominante é o feminino. Mas sozinha, será que chega longe? A mulher independente e autossuficiente, dona da casa e estruturadora da família - além de sempre dona de casa - é uma realidade atual, mas ainda assim precisa incorporar a mulher sensual e sedutora, para satisfazer "o seu homem". Os editorais da revista Vogue Brasil não apenas mostram os acessórios e vestuários que estão na moda. Eles mostram o imaginário criado para essas mulheres, o ambiente de sonho e possibilidades, que justamente por ser tão “irreal”, habita o imaginário. As informações ali presentes atingem diretamente a área dos desejos, e trabalham para criar um local dentro da nossa percepção que seja 
referência, e não apenas um apelo para o consumo imediato. Os editoriais estão criando e preenchendo o nosso imaginário com as informações que são cuidadosamente escolhidas. O fetiche, fazendo parte dessa construção, atua nesse imaginário estruturado; nos mostra as opções de postura e comportamento - mesmo que em alguns momentos isso aconteça sutilmente - que podemos incorporar.

Um amigo disse, há pouco tempo: “o fetiche é como a pornografia né? É difícil de definir, mas todo mundo sabe o que é”. Essa sua fala chama a atenção principalmente por informar que "todo mundo sabe o que é", demonstrando justamente que existe uma estética relacionada ao fetiche que já está incorporada ao imaginário coletivo, ao saber comum. Perceber essa estética presente na revista feminina mais importante do país não apenas em termos de circulação, mas principalmente pelo nome que carrega e o que representa - e de maneira recorrente, demonstra em dados essa informação trazida tão casualmente em uma conversa de restaurante.

Não há uma previsão de como o fetiche será utilizado e retratado nos próximos anos pela moda, mas imaginamos que ele deva ser popularizado cada vez mais, enquanto o sexo puder vender e enquanto as revistas femininas de moda precisarem ditar qual papel a mulher deve exercer dentro da sua própria vida. Ficaram claros os múltiplos papéis e identidades possíveis às mulheres, a partir da presença dos objetos e acessórios fetichistas, e da maneira com que os corpos são retratados. Resta saber qual papel você irá escolher. 


\section{Referências}

ANGELETTI, Norberto; OLIVA, Alberto. In Vogue: the illustrated history of world's most famous fashion magazine. Vogue, New York: Rizzoli International Pulications, Inc., 2006.

BARTHES, Roland. Sistema da moda. São Paulo: Ed. Nacional: Ed. da USP, 1979.

BINET, Alfred. Le Fétichisme Dans L'Amour. In: Revue Philosophique de la France et de l'Étranger. França: Presses Universitaires de France, 24 de agosto de 1887, p. 143-167.

BOTTI, Mariana Meloni Vieira. Fotografia e fetiche: um olhar sobre a imagem da mulher. Cad. Pagu, Campinas, SP: n. 2, p.103-131,2003.

BROWN, Susanna. Primeiras Fotografias de Moda. In: HACKING, Juliet (Org.). Tudo sobre fotografia. Rio de Janeiro: Sextante, 2012. p. 260-267.

BROWN, Susanna.. Moda e Estilo. In: HACKING, Juliet (Org.). Tudo sobre fotografia. Rio de Janeiro: Sextante, 2012, p. 488-493.

BUSATO, Claudia. Visões do consumo: um diálogo com o mundo. Prosa UNIDERP (Universidade para o Desenvolvimento do Estado e da Região do Pantanal). v. 1, n. 1, set/2001. p. 161-172.

CANCLINI, Néstor García. Consumidores e cidadãos: conflitos multiculturais da globalização. Rio de Janeiro: Ed. UFRJ, 1995.

DEBORD, Guy. A sociedade do espetáculo: comentários sobre a sociedade do espetáculo. Rio de Janeiro: Contraponto, 2000.

FREUD, Sigmund. Uma neurose infantil e outros trabalhos. ESB Vol. XVII. Rio de Janeiro: Imago, 1996.

FREUD, Sigmund Escritos sobre a psicologia do inconsciente. Vol. II: 1915-1920. Rio de Janeiro: Imago, 2006.

FREUD, Sigmund. Um caso de histeria, três ensaios sobre a teoria da sexualidade e outros trabalhos. Vol. VII: 1901-1905. Rio de Janeiro: Imago, 200.

FREUD, Sigmund. Fetichismo (1927). In: Escritos sobre a psicologia do inconsciente. Vol. III: 1923-1940. Rio de Janeiro: Imago, 2007.

HOUAISS, Antonio. Dicionário eletrônico Houaiss da língua portuguesa. Versão 1.0.5a, 2002.

JOLY, Martine. Introdução à análise da imagem. Campinas, SP: Papirus. 14. ${ }^{a}$ edição, 2010. 
JOLY, Martine. A imagem e os signos. Lisboa, Portugal: Edições 70, 2005.

JOLY, Martine. A imagem e a sua interpretação. Lisboa, Portugal: Edições 70, 2002.

JUSTO, José Sterza. A Psicanálise Lacaniana e a educação. In: CARRARA, Kester. (Org.)

Introdução à psicologia da educação: Seis Abordagens. São Paulo: Avercamp, 2004.

KAUFMANN, Pierre. Dicionário enciclopédico de psicanálise: o legado de Freud e Lacan. Rio de Janeiro: Jorge Zahar Ed., 1996.

KRAFFT-EBING, Richard von. Psychopathia sexualis: as histórias de caso. Tradução de Claudia Berliner. São Paulo: Martins Fontes, 2000.

LACAN, Jacques. O seminário: livro 4, a relação de objeto. Rio de Janeiro: Jorge Zahar Ed., 1995.

LIPOVETSKY, Gilles. O império do efêmero: A moda e seus destinos nas sociedades modernas. São Paulo: Companhia das Letras, 1989; 2009.

MARX, Karl. O caráter fetichista da mercadoria e seu segredo. In: MARX, Karl. O capital: crítica da economia política. Tradução de Regis Barbosa e Flávio R. Kothe. São Paulo: Abril Cultural, 1983. Vol. 1, Livro Primeiro, seção 1, Cap. 1, p. 70-78.

NOVELLI, Daniela. Juventudes e imagens na revista Vogue Brasil (2000-2001). 275 p. Dissertação (Mestrado em História) - Universidade do Estado de Santa Catarina, Centro de Ciências Humanas e da Educação, Programa de Pós-Graduação em História (Florianópolis, 2009.

PSYCHIATRIC Disorders: Transvestic Fetishism. Allpsych online: the virtual psychology classroom, Last Updated: 29 nov. 2011. Copyright 1999-2003 AllPsych and Heffner Media Goup, Inc.. Disponível em: <http://allpsych.com/disorders/paraphilias/transvestite.html>. Acesso em: 23 fev. 2013.

RAMOS, Krishna Figueiredo de Almeida. Sedução e desejo: representações da mulher nos anúncios de perfumes femininos. 144 p. Dissertação (Mestrado em Comunicação) Universidade de Brasília, Programa de pós-graduação em Comunicação da Faculdade de Comunicação, Brasília, 2006.

SELLERS, Terence. Introdução. In: KRAFFT-EBING, Richard von. Psychopathia sexualis: as histórias de caso. Tradução de Claudia Berliner. São Paulo: Martins Fontes, 2000. p. 7-21.

SHAKTI, Agni. Dicionário de fetiches e BDSM. São Paulo: Ideia \& Ação, 2008. 
SILVA, Vivianne Cabral e. Construção de identidade de marca, fotografia de moda e erotismo: As campanhas Sisley. 2007, 00 f. Dissertação (Mestrado em Cultura Visual), Universidade Federal de Goiás, Programa de pós-graduação em Cultura Visual da Faculdade de Artes Visuais , Goiânia, 2007.

STEELE, Valerie. Fetiche: moda, sexo \& poder. Tradução de Alexandre Abranches Jordão. Rio de Janeiro: Rocco, 1997.

STEELE, Valerie. Fashion and eroticism: ideals of feminine beauty from the victorian era to the jazz age. New York: Oxford University Press, 1985.

Recebido em: 19/04/2015 Aprovado em: 26/05/2015

Universidade do Estado de Santa Catarina - UDESC Programa de Pós-Graduação em Educação - PPGE Revista Linhas

Volume 16 - Número 32 - Ano 2015 revistalinhas@gmail.com 